Tea Baldigara, Ph.D.

University of Rijeka, Faculty of Tourism and Hospitality Management, Opatija

UDK 338.483(497.5)

\title{
ANALYSING TOURISTS INFLOWS IN THE TOWN OF OPATIJA
}

Abstract: This study attempts to identify an autoregressive distributed lag model (ADLM) as the data generating process of tourism demand in Opatija approximated by tourist nights. Empirical finding yield to the conclusion that the final model passes all the diagnostic checking and that model fits the data reasonably well throughout the sample period. Quantitative researches of tourism demand and accurate forecasts generating should be at the basis of efficient and effective planning and decision-making. Tourism demand modelling and forecasting, as many studies and researches demonstrated, is a relevant issue that can be helpful to all the stakeholders involved in the tourism and hotel industry. The accurate and timely forecast can anticipate future trends and allow to plan, organise and structure tourism capacities and supply more efficiently.

Key Words: Opatija, tourism demand, tourists nights, ADLM.

\section{Introduction}

Although Opatija is undoubtedly a distinguished Croatian tourist destination with a 175-year long tourist tradition, new market trends, the technological revolution, and strong competition, there are new challenges towards future tourism and hotel industry growth and development.

To achieve higher competitiveness, better performance results, attract more guests and tourists, reduce seasonality, build a stronger destination identity and brand Opatija, there is a need of cooperation and networking among all the stakeholders involved in the tourism sector. At the basis of future expansion activities should be, among others, performance indicator quantitative analysing and modelling. Quantitative modelling assumes a crucial role in the tourism industry, which needs accurate demand forecasts in order to perform efficient and effective planning and decision-making. Accurate tourism demand forecasts improve the efficiency of business decision-making and improve performances. Tourism demand modelling and forecasting, as many studies and researches demonstrated, is a relevant issue that can be helpful to all the stakeholders involved in the tourism and hotel industry. Accurate forecasts of tourism demand provide crucial information for tourism policy-making in both the government and business sectors (Shen, Li, Song, 2011). Accurate and timely forecasts can anticipate future trends and allow to plan, organise and structure tourism capacities more efficiently.

Given the importance of the tourism sector for the town of Opatija and its economic and social impact on one hand, and the necessity of accurate tourism performance and indicator forecasts on the other, this study aims to model the number of tourists' nights as a proxy of tourism demand in the destination.

\section{Opatija- Tourism in Figures}

On the top ten list on the cities and municipalities that achieved the best tourism and hotel industry business results in Croatia in 2018 Opatija,was ranked at eight position (MINT, 2018). 
According to the Tourism Board of Opatija (Cvjetović, 2019) in August 2019 there were 62676 registered tourists (an increase of 7\% compared to August 2018) and 261864 tourist nights (an increase of $5 \%$ compared to August 2018). The majority of tourist turnover $(55,37 \%)$ was realised in hotel accommodation facilities, and namely 144483 nights, following the private accommodation sector with 108236 (or 41,48\%) nights. Among the origin tourists' countries, Germany has traditionally been one of the most important generators of tourist flows in Opatija followed by Austria, Italy, Hungary, Great Britain and Switzerland. Domestic tourism revealed an increase in nights and arrivals of $7 \%$.

According to official data from the eVisitor information system for check-in and check-out of tourists and the Kvarner tourist board (Jonjić, 2018), there is an increasing trend of overnight stays in luxury accommodation facilities. Specifically: there was an increase in registered overnights stays in the hotels of about $5 \%$, but the increase in 5 * hotels was $8 \%$. The private sector followed the same trend, with an increase of about $11 \%$, but in private accommodation with $5 *$ the increase was of about $44 \%$. The average stay of a tourist was estimated at 4,2 days. Considering the tourists' age, the most nights were realised by tourist between ages 15-50. That fact is in accordance with the tourist tradition of Opatija, which is widely recognized as a family tourist destination. The same source reported that the average tourist in Opatija is 46 years old; he is loyal and has travelled to Croatia six or more times. The average household income of tourists visiting Opatija is $€ 3,000$ or more and they spend about $105 €$ per day.

When considering tourism traffic and tourist accommodation facilities in Opatija. Table 1 gives a summary of the number of beds, nights and arrivals in 2018 .

Table 1: Opatija in figures

\begin{tabular}{|c|c|c|c|}
\hline & Beds & Nights & Arrivals \\
\hline Opatija & 14115 & 1350061 & 436678 \\
\hline $\begin{array}{c}\text { Primorska-goranska } \\
\text { County }\end{array}$ & 214647 & 15284346 & 2909914 \\
\hline Croatia & 1313163 & 89651789 & 18666580 \\
\hline
\end{tabular}

Source: https://www.dzs.hr/default.htm, Statistical reports 1639/2019

As depicted in Table 1, Opatija accounted in 2018 for $7 \%$ of the number of beds, $9 \%$ of tourist nights, and $15 \%$ of tourists' arrivals in Primorsko-goranska County. On the national scale, that is $1 \%$ of beds, $1.5 \%$ of tourist nights and about $2 \%$ of total tourist arriv-
als.The importance and the level of tourism and hotel industry performance in Opatija can be summarised by analysing the number of nights, arrivals and tourists accommodation facilities from 2007 to 2017. 
Figure 1: Tourists nights, arrivals and accommodation from 2007 to 2017

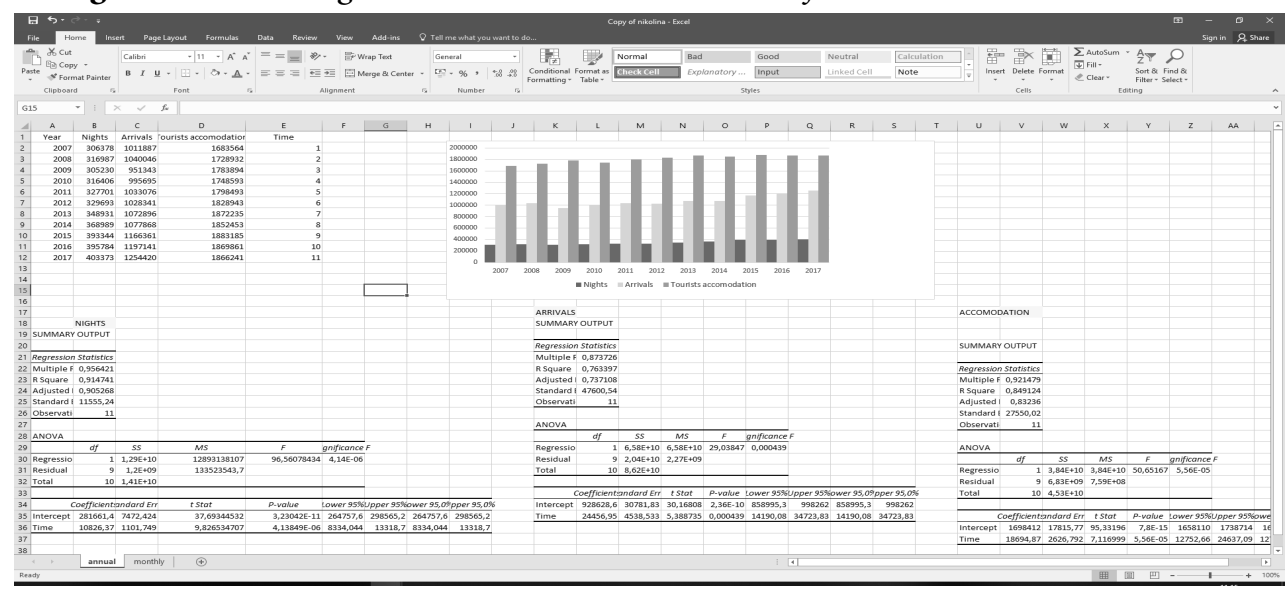

Source: Author's calculations

Figure 1 reveals a slight upward trend of selected tourism performance indicators. Assuming that tourist arrivals, overnight stays and accommodation facilities will follow the present trend, future values extrapolation can be performed using adequate trend models. Considering the data generating process, the single estimated trend model equations follow.

The linear trend equation for tourist nights is given by:

(1)
The second-order polynomial trend equation for tourist arrivals is given by:

\section{(2)}

The second-order polynomial trend equation for tourist accommodation facilitiesis given by:

\section{(3)}

Figure 2 depicts the actual and fitted data.

Figure 2: Tourists nights, arrivals and accommodation: actual vs fitted data from 2007 to 2020

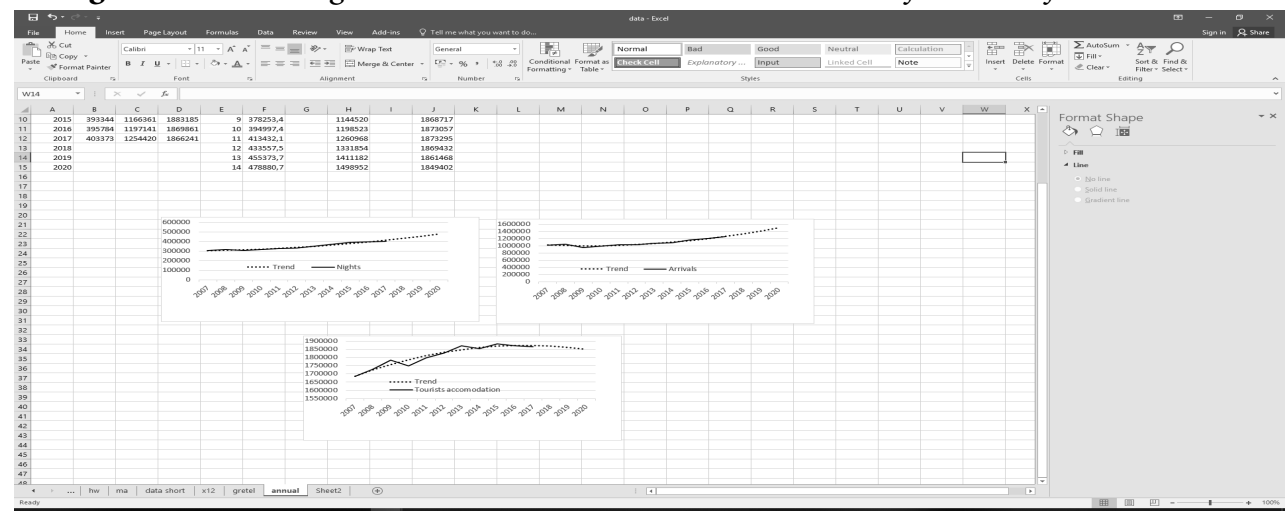



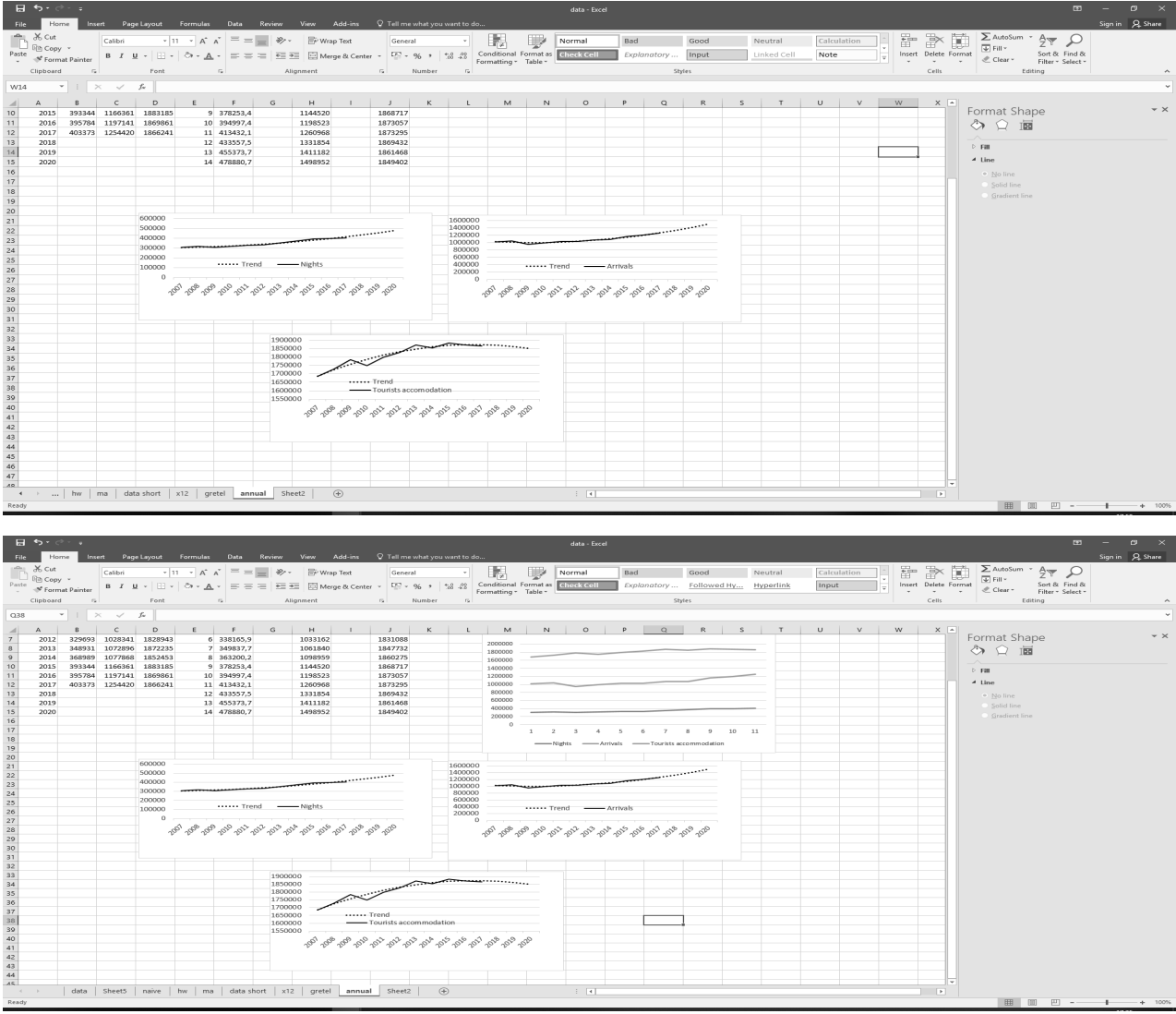

Source: Author's calculations

modation facilities until 2020 has been per-

Based on estimated trend models, foreformed (Table 2). casts of tourist arrivals, nights and accom-

Table 2: Tourists nights, arrivals and accommodation forecasts

\begin{tabular}{|r|r|r|rr|}
\hline Year & \multicolumn{1}{|c|}{ Nights } & \multicolumn{1}{c|}{ Arrivals } & \multicolumn{2}{|c|}{ Tourists accommodation } \\
\hline 2018 & 433557,5 & 1331854 & & 1869432 \\
\hline 2019 & 455373,7 & 1411182 & 1861468 \\
\hline 2020 & 478880,7 & 1498952 & & 1849402 \\
\hline
\end{tabular}

Source: Author's calculations 
The overall trend of tourist and hotel industry expansion can be also noticed when dealing with the popular Google search en- gine and its Google Trends service. The interest in Opatija can be illustrated through monthly Google Trends indices (Figure 3).

Figure 3: Google Trends monthly indices-search term "Opatija Croatia" from January 2013 to December 2017

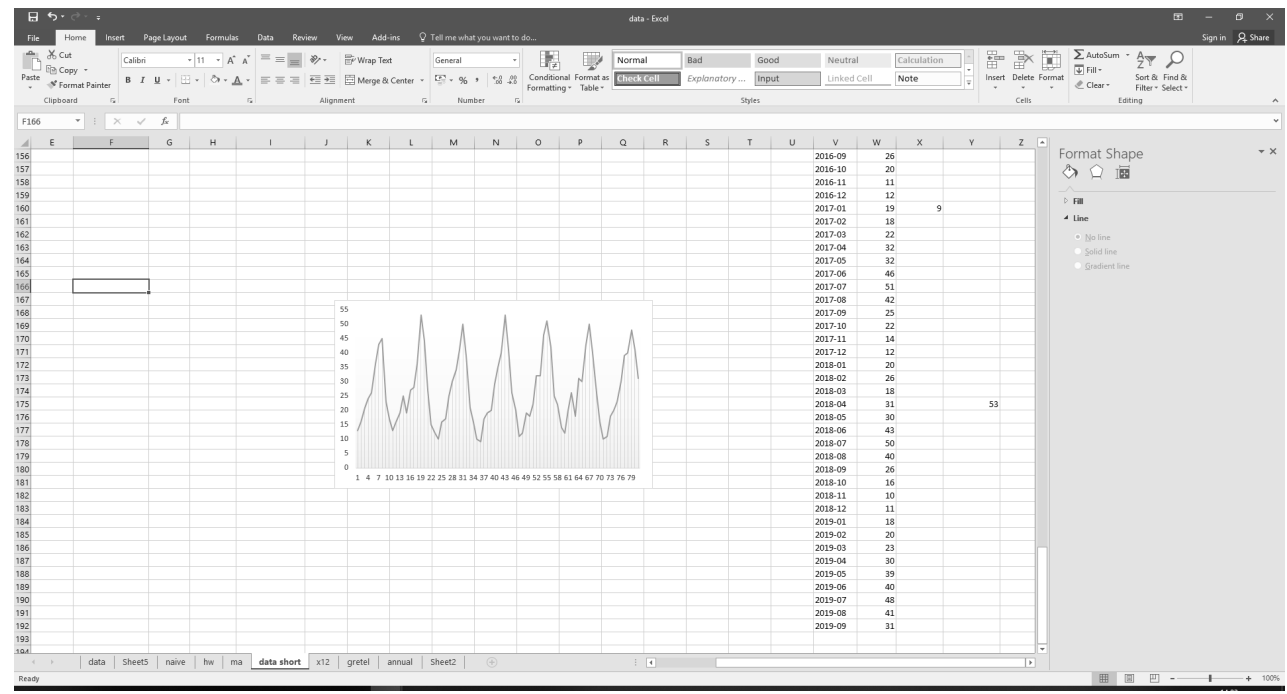

Source: Author's calculations

As depicted in Figure 3 the interest expressed for Opatija denotes as well a pronounced seasonal component, reflecting presumably the seasonal character of the tourism itself in the destination.

\section{Literature methodology and data}

In this study, the modelling approach is implemented in the attempt to identify an autoregressive distributed lag model (ADLM) as the data generating process of tourism demand in Opatija. Generally, a simple tourism demand model for a destination can be specified as (Song, Witt and Li, 2009):

where is the tourism demand (normally measured by total/per capita visits/expenditure to a destination $i$ ); is the measure of income in the tourism generated country $j$; and is a price variable which represents living costs for tourists in destinationi. The following gives an insight into theoretical and methodological foundations as the basis for the modelling approach implemented in this study.

\section{Literature review}

In a comprehensive study Song and $\mathrm{Li}$ (Song and $\mathrm{Li}, 2008$ ) carried out a review of published studies on tourism demand modelling and forecasting and concluded that one of the major advantages of econometric approaches over time-series models lies in their ability to analyse the causal relationships between the tourism demand variable and its influencing factors. Among the frequently used econometric models, the autoregressive distributed lag models (ADLM) 
can be mentioned. Since the mid-1990s, dynamic models, for example, a number of specific forms of the autoregressive distributed lag models (ADLMs), (Hendry 1995, p.232) including ECMs have appeared in the tourism demand literature (Song, Witt, Li, 2005). Ismail,Iverson and Cai (Ismail, Iverson and Cai, 2000) used the ADLM to explain the arrival patterns of Japanese visitors to Guam. In the study, they concluded that the previous arrivals patterns were a significant predictor for future tourism demand. Croes and Vanegas (Croes and Vargas, 2005) used the linear and the log-linear ADLM in modelling tourist arrivals in Aruba from the United States, The Netherlands and Venezuela. They specified a dynamic econometric model for explaining both, short and long term responses and concluded that the double-log model fits the data in terms of statistical significance of the estimated coefficients. Lim (Lim, 2004) used the autoregressive double-log model to explain the patterns of outbound South Korean tourism to Australia and to analyse demand elasticities. Song, Wong, Chon (Son, Wong, Chon, 2003) has used four types of model, such as seasonal auto-regressive integrated moving average model (SARIMA), auto-regressive distributed lag model (ADLM), error correction model (ECM) and vectorautoregressive model (VAR) to forecast tourism demand for Hong Kong by residents from ten major origin countries. The empirical results show that forecast combinations do not always outperform the best single forecasts. Therefore, a combination of empirical models can reduce the risk of forecasting failure in practical.ShenmLi and Song used five modern econometric models to forecast international tourism demandand generate individual ex-post forecasts: the READLM, WB-ECM, JMLECM, VAR model and TVP model. (Shen, Li, Song, 2011).

\section{The dataset}

Tourism demand can be measured in a variety of ways (Song, Gang, Witt, 2009). A commonly used tourism demand measure is the number of tourist nights spent by the country of origin in a tourist destination. Data on tourist's nights should be considered as a significant source of information for all the stakeholders involved in the tourism and hotel industry since they provide valuable indicators in the process of organising, planning and successful decision-making. As a proxy of the tourism demand in Opatija, this study considers the total (domestic and foreign) nights (TN) spent at tourist accommodation establishments; monthly data from January 2013 to December 2017. Data are collected from the Croatian Bureau of Statistics web site.

Figure 4: Tourists nights: monthly data from January 2013 to December 2017

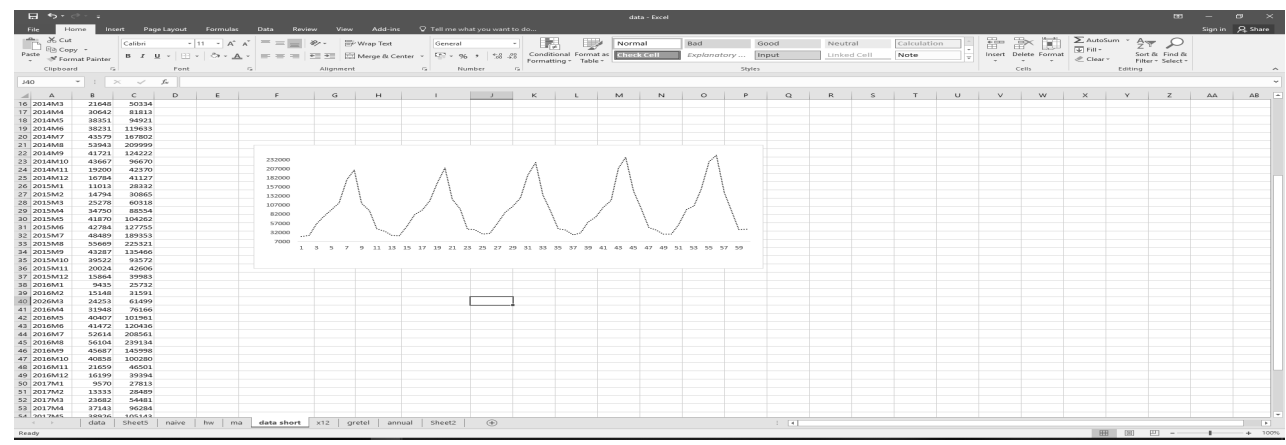

Source: Author's calculations 
Figure 4 reveals that the time-series presents strong, seasonal influences and an upward trend component. Nevertheless, there is evidence of irregular oscillations, too, suggesting a non-stabilisation of the average and variance. It is well known that the hotel industry in Croatia is pronouncedly seasonal sensitive. In fact, the number of tourist nights is at its maximum level in the summer period from July to August, with a drastic fall in the period from October to May. It is clearly shown that the seasonal patterns are rather consistent over the analysed period. The observed time series consists of 59 observations with an average monthly value of 95876,47 registered tourists nights with a standard deviation of 63109,09 nights. The maximum number of
245628 tourist's nightswas registered in August 2017, while the lowest number of 21180 nights was recorded in January 2013. The explanatory variables are as follows:

- TA: total, domestic and foreign, tourist arrivals at tourist accommodation establishments; monthly data from January 2011 to November 2018; collected from the Croatian Bureau of Statistic Statistical Database and the Eurostat Database

- GT: research interest indices for the term "Opatija, Croatia", monthly data from January 2013 to December 2017; search interest: worldwide, collected fromhttps:// trends.google.it/trends/?geo=IT.

Figure 5 graphically depicts the explanatory variables chosen to build the ADLM model.

Figure 5: The explanatory variables

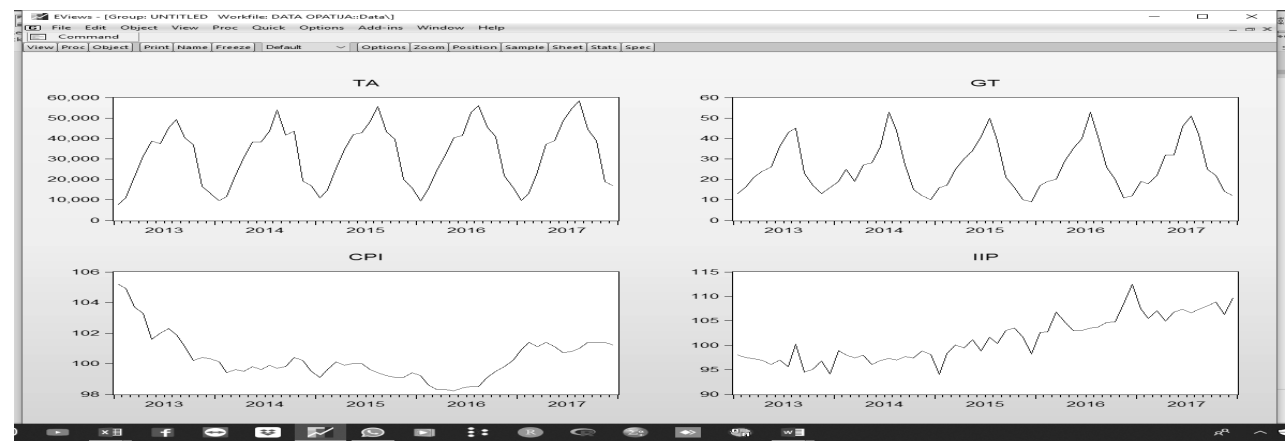

Source: Own elaboration

A preliminary analysis of the potential relationship existing between the dependent and the explanatory variables is given by performing the correlation analysis (Table 3 ).

Table 3: Dependent and explanatory variables correlation coefficients

\begin{tabular}{|c|c|c|c|}
\hline & $T N$ & $T A$ & \\
\hline$T N$ & 1 & & \\
\hline$T A$ & 0,94 & 1 & 1 \\
\hline$G T$ & 0,85 & 0,79 & \\
\hline
\end{tabular}

Source: Own elaboration 
The correlation coefficient assumes high values, presuming the existence of a relationship between the chosen explanatory variables and the dependent variable.

\section{The theoretical model}

According to Song, Witt and Li (Song, Witt \&Gang, 2009) if a dependent variable is determined by $k$ explanatory variables, the data generating process may be written as an autoregressive distributed lag model $(A D M L)$ :

\section{(5)}

where $p$ is the lag length and is the error term which is assumed to be normally distributed with zero mean and constant variance, ().

The initial specification of the general autoregressive distributed lag model in (5) contains all possible explanatory variables and the type of the actual data used determines the lag length. The final model should contain only significant explanatory. The final specific model should be simple in structure and possess the desirable statistical properties. It should display no autocorrelation, heteroscedasticity, misspecification, forecasting failure or non-normality (Song, Smeral, Li \&Chen, 2008).

\section{Empirical findings}

Before approaching the modelling process, and in order to stabilise the mean and the variance, data are being pre-processed by logarithmic transformation and differencing. The augmented Dickey-Fuller (ADF) test was used to check the stability of the series. The testing results showed that the first order differenced series were all stationary. The series are all integrated of order 1or I(1).

In modelling the number of nights in
Opatija it is assumed that the initial data generating process may be written as an autoregressive distributed lag model as follows:

After identifying the initial model, the estimation and diagnostic checking were performed and repeated until obtaining a sound model. The Ordinary least squares (OLS) method was used to identify the final ADML model as the data generating process of the number of tourists nights in Opatija and a regression equation was generated as follows:

\section{S.E. of regression $=0,07(7)$}

\section{$\mathrm{RSS}=0,21$}

The constant term and the lagged GT variable were not significant and were removed from the final model. All the performed diagnostic statistics show that the model passes all the tests. The results of the Ramsey RESET test results confirmed that the model is correctly specified. The coefficient are all statistically significant. The coefficient of the lagged explanatory variable tourism arrivals indicates that if tourism arrivals in time $t-12$ increase of $1 \%$, the number of tourists nights at time $t$ will decrease for $0,82 \%$. A possible interpretation could be the lack of tourist's loyalty and their non-willingness to visit the destination again.

Double-logarithmic regression has been the predominant functional form in tourism demand modelling studies over the past few decades (Song \& Li, 2008). The autoregressive double log model has the advantage that the estimated parameters can be interpreted as demand elasticities. (Song, Witt, 2003) In fact, one important feature of the double-log regression model is that the slope coefficient measures the elasticity of with respect to , that is the percentage change in for a given percentage change in (Gujarati, Porter, 2009).As depicted in Figure 6 the model fits the data reasonably well throughout the sample period. 
Figure 6. Monthly tourists' nights: actual versus fitted; Time bounds: 2013m1-2017m12

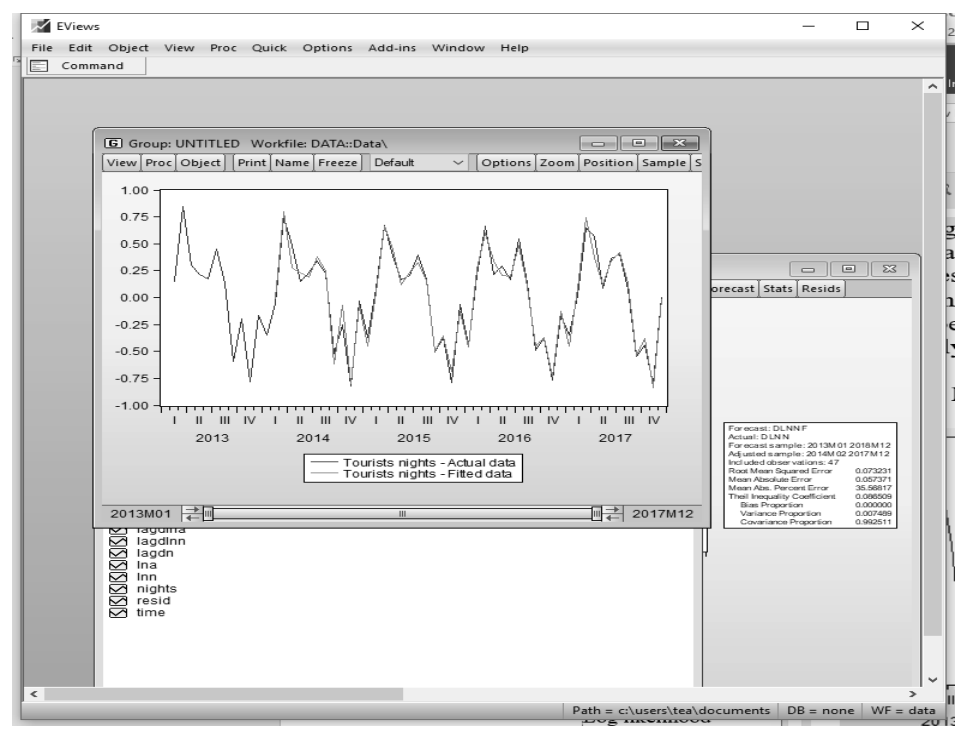

Source: Own elaboration

The model fits the general movement of the analysed series during the entire sample period. The forecast results are reasonably good; the predicted values, in fact, are quite close to the actual values. As the Theil's Ucoefficient is less than one $(0,08)$, the model performs well in forecasting tourists nights.

\section{Conclusions}

Opatija is among the most significant tourist destination in Croatia. This paper seeks to model tourism demand in Opatija. The monthly number of tourism nights as taken as a proxy of the tourism demand in the destination. In the study it is supposed that the data generating process could be written as a general autoregressive distributed lag model. The set of explanatory variables consisted of two independent variables, namely, tourist arrivals and the Google trends search indices for the term "Opatija Croatia". The model was estimated using the OLS method. The diagnostic checking and model performance evaluation yield the final model as a double-log model, with only significant explanatory variables, simple in structure and possessing the desirable statistical properties. Furthermore, the tests results confirmed that the selected model fitted the empirical time-series well throughout the entire analysed period. The Ramsey RESET test results confirmed that the model is correctly specified. The model performance evaluation could be improved by including more explanatory variables that, a more detailed analysis confirms to be significant in explaining the determinants of tourism demand in the destination.

Such conclusion is in accordance with the fact that, in order to achieve better competitiveness and performance results, build a stronger destination identity and brand Opatija, there is a need of cooperation and networking among all the stakeholders involved but also accurate quantitative analysis of tourism demand determinants. Quan- 
titative modelling assumes a crucial role in the tourism industry, which needs accurate demand forecasts in order to perform efficient and effective planning and decisionmaking

\section{Bibliography}

Croes, R. R. \&Vanegas, M. (2005) An econometric study of tourist arrivals in Aruba and its implications. Tourism Management, 26, 879-890.

Cvjetović, N. (2019) Turističkestatistike u plusu@Opatija. Available at:http:// poduckun.net/turisticke-statistike-u-plusu-opatija/ [15 September 2019]

Croatian Bureau of Statistics (2019) Statistical reports 1639/2019. Available at: https://www.dzs.hr/default.htm[14 September 2019]

Gujarati, D. N. \& Porter, D. C. (2009) Basic Econometrics. Boston: McGraw-Hill - International Edition.

Hendry, D. F. (1995) Dynamic Econometrics: Advanced Text in Econometrics, Oxford: Oxford University Press.

Ismail, J. H., Iverson, T. J., \&Cai, L. A. (2000) Forecasting Japanese arrivals to Guam: An empirical model. Journal of Hospitality and Leisure Marketing, 7, 381-396.

Jonjić V. (2018) Brendiranje Opatije kao destinacije za mlade 7. Riviera News. Available at: https://www.rivijeranews. hr/brendiranje-opatije-kao-destinacije-za-mlade-7/ [15 September 2019]

Lim, C. (2004) The major determinant of Korean outbound travel to Australia. Mathematics and Computers Simulation, 64, 447-485.

MINT (2018) Turizam u brojkama 2018. Available at: (https://mint.gov.hr/ UserDocsImages/AA_2018_cdokumenti/190614_HTZ\%20TUB_2018_ hrv.pdf ) [15 September 2019]
Shen, S., Li, G., \& Song, H. (2011) Combination Forecasts of International Tourism Demand. Annals of Tourism Research, 38 (1), 72-89.

Song H., Witt, S. F. \& Li, G. (2005) Recent Developments in Econometric Modelling and Forecasting. Journal of Travel Research, 44, 82-99.

Song, H. \& Witt, S. F. (2003) Tourism Forecasting: The General-to-Specific Approach. Journal of Travel Research, 42, 65-74.

Song, H., \& Li, G. (2008) Tourism demand modelling and forecasting - A review of recent research. Tourism Management, 29, 203-220.

Song, H., Smeral, E., Gang, L. \& Chen, J.L. (2008) Tourism Forecasting: Accuracy of Alternative Econometric Model Revisited, WIFO Working Papers 326, WIFO.

Song, H., Witt, S., \& Gang, L. (2009) The Advanced Econometrics of Tourism Demand, London:Routledge.

Song, H., Wong, K. K. F., \& Chon, K. K. S. (2003) Modelling and forecasting the demand for Hong Kong tourism, Hospitality Management, 22, 435-451. 